\title{
Epidemiological Aspects of Chronic Renal Failure at Dipumba Hospital in the City of Mbujimayi/RD. Congo
}

\author{
Claude Tshibangu Lukusa', Felly Kasongo Ngoyi', Léon Mbenga Kasela1, \\ Elisée Ntambua Mbombo', Georges Kabeya Kalala², Chris Kabangu Mukanya², \\ Jean Christophe Bukasa Tshilonda2 ${ }^{2}$ Matthieu Lubo Mumbiyi ${ }^{3}$, Théophile Lombe Mibanga ${ }^{4}$, \\ André Kazadi Mukendi2
}

${ }^{1}$ Official University of Mbujimayi, Mbujimayi, RD. Congo

${ }^{2}$ Higher Institute of Medical Techniques of Mbujimayi, Mbujimayi, RD. Congo

${ }^{3}$ Higher Pedagogical Institute of Muene Ditu, Muene Ditu, RD. Congo

${ }^{4}$ University of Kabinda, Kabinda, RD. Congo

Email: jcbukasa4@gmail.com

How to cite this paper: Tshibangu Lukusa, C., Kasongo Ngoyi, F., Mbenga Kasela, L., Ntambua Mbombo, E., Kabeya Kalala, G., Kabangu Mukanya, C., Bukasa Tshilonda, J.C., Lubo Mumbiyi, M., Lombe Mibanga, T. and Kazadi Mukendi, A. (2021) Epidemiological Aspects of Chronic Renal Failure at Dipumba Hospital in the City of Mbujimayi/RD. Congo. Open Access Library Journal, 8: e7413.

https://doi.org/10.4236/oalib.1107413

Received: April 12, 2021

Accepted: June 12, 2021

Published: June 15, 2021

Copyright $\odot 2021$ by author(s) and Open Access Library Inc.

This work is licensed under the Creative Commons Attribution International License (CC BY 4.0).

http://creativecommons.org/licenses/by/4.0/

\begin{abstract}
Introduction: The objective of this study was to determine the prevalence, stages, diagnosis and evolution of chronic renal failure in the town of Mbujimayi and specifically at Dipumba Hospital. Material and Methods: This was a retrospective, descriptive and cross-sectional study, spanning a period of 6 years, i.e. from 01/01/2014 to 12/31/2019 at DIPUMBA hospital. The study involved 33 patients with CKD. Results: The hospital frequency was $1.22 \%$. The age of our patients varied between 35 and 90 years with an average age of $58.2 \pm$ 11.7 years. The age group most affected was that of 50 to 59 years in a proportion of $39.39 \%$. Men were the most affected with 26 cases (78.79\%) against 7 (21.21\%) for women. The reasons for admission were dominated by oligo-anuria, digestive disorders, dyspnea and physical asthenia. Arterial hypertension, diabetes mellitus and acute renal failure were the antecedents found in the majority of our patients, i.e. in $90.91 \%$ respectively; $84.85 \%$ and $66.67 \%$ of cases. The majority of patients, $60.6 \%$, had end-stage chronic renal failure. The healthy diet + medication was the most recommended treatment. The majority of cases, or $66.67 \%$, resulted in stabilization against $33.33 \%$ of death cases. Conclusion: Chronic renal failure is a frequent pathology in our environment. It affects patients from their thirties, of both sexes. The majority of patients consult for oligo-anuria, digestive disorders, dyspnea and physical asthenia. High blood pressure and diabetes mellitus are the most common history. Most patients are admitted at the terminal stage. The lethality is quite high (33.33\%).
\end{abstract}




\section{Subject Areas}

Epidemiology

\section{Keywords}

Epidemiology, Chronic Renal Failure, Dialysis

\section{Introduction}

Chronic kidney disease (CKD) is a major public health problem in both developed countries and in countries in development paths [1]. His real extent in Africa, in the Democratic Republic of Congo (DRC) and Mbujimayi remains unknown [2].

It is a serious disabling pathology, constantly increasing and the treatment of which is particularly restrictive and expensive. It therefore represents a public health issue both from the point of view of management of the resources devoted to this pathology and in the preparation of patients who will require renal replacement therapy.

Most if not all kidney disease is progressive, although the rate of progression is extremely variable from one individual to another. Slow down the progression which is one of the major challenges of 21st century nephrology [3].

According to the WHO [4], kidney disease is described as the most neglected chronic disease. In 2015, nearly 600 million people, or $5 \%$ of the world's population, had chronic kidney disease. In some low-income countries, the inaccessibility of replacement therapy remains the great unresolved challenge today. In Africa, its exact prevalence according to some authors is better documented only in a few countries. In sub-Saharan Africa, this has been estimated at 13.9\% [5]. In Côte d'Ivoire, it is $5.8 \%$ of patients admitted to hospital, of which $5 \%$ of patients have access to replacement therapy [6]. In the Democratic Republic of Congo, studies conducted on its prevalence in 2009 in the city province of Kinshasa estimated it at $12.4 \%$ and $19.8 \%$ [7] [8].

The modalities of the management of IRC were presented at the Quadrimed congress in 2013. Since then, interesting novelties have been published and will be the subject of this update. Kidney disease is prevalent in 15\% of the population according to US statistics. The causal diagnosis includes approximately $50 \%$ of diabetic and hypertensive patients. Chronic kidney disease is a notorious independent risk factor that increases exponentially with loss of kidney function; it is therefore of the utmost importance to slow down its progression in order to avoid the outcome of replacement therapy and to protect the patient from cardiovascular complications, whether fatal or not. In addition, the art of nephrological monitoring consists in controlling collateral disorders secondary to renal disease which may also participate in the progression of CRF.

Optimal treatment of arterial hypertension is certainly the most important con- 
dition to consider in order to slow the progression of renal failure [9].

The recent SPRINT study published at the end of 2015, with a specific blood pressure measurement protocol (self-measurement in a standardized situation), demonstrated a reduction in cardiovascular morbidity and mortality in non-diabetic patients at high cardiovascular risk with a target value of systolic blood pressure less than $120 \mathrm{mmHg}$ (mean $121.5 \mathrm{mmHg}$ ) in comparison with standard treatment aiming for a systolic pressure value below $140 \mathrm{mmHg}$ (mean $134.6 \mathrm{mmHg}$ ) [10]. Unfortunately, the progression of renal failure could not be slowed down by the intensive diet with lower blood pressure values.

As hygieno-dietetic measures, it should be noted that the reduced salt intake makes it possible to better control arterial pressure (5 to $6 \mathrm{~g}$ of salt/day) and to reduce proteinuria; this is an important step to take in any patient with kidney failure. There are of course other measures to consider, such as stopping smoking and the fight against sedentary lifestyle. Finally, correcting hyperlipidemia is also important for reducing cardiovascular risk and possibly halting the progression of CRF [11].

Prevention of terminal CKD relies on a thorough knowledge of the risk factors that determine its frequency.

There are 2 levels of prevention of CRF:

- Primary prevention which aims to reduce the incidence of kidney disease.

- Secondary prevention aims to improve the quality of life or survival of treated patients and to reduce co-morbidities [12].

The present study reports the epidemiological aspects of chronic renal failure in the town of Mbujimayi and specifically at the Dipumba Hospital, which aspects will put the ears of practitioners on the need for early diagnosis, prevention and treatment. Good therapeutic orientation of patients.

In view of the problems posed by chronic renal failure, and its epidemiological aspects which are poorly understood in the general population, we proposed to carry out this work intended to determine the epidemiological aspects linked to chronic renal failure in our environment.

\section{Material and Method}

The study was carried out in the internal medicine department of the Dipumba Hospital located in the Kanshi Commune, Mbujimayi city, Kasai-Oriental Province, in the Democratic Republic of Congo. The study population consisted of all the patients who consulted the Dipumba internal medicine department during the study period and the sample drawn from this population was of simple random type consisting of 33 patients who were admitted for renal failure. chronic at Dipumba hospital. The method used in this study was retrospective, descriptive and cross-sectional, spanning a period of 6 years, i.e. from 01/01/2014 to $12 / 31 / 2019$ at DIPUMBA hospital. To collect the data, we used a form which was used for this purpose and these data were encoded on a table in Microsoft Excel 2010 software and processed with the computer software Epi info Atlanta 7.1.1.14 CDC USA 2013. The data analyzed were then presented in tabular form. 


\section{Results}

Table 1 shows us that during the study period, 2716 patients were admitted to the internal medicine department for various pathologies, of which 33 were for chronic renal failure, i.e. a prevalence of $1.21 \%$.

Table 2 shows us that the incidence of IRC is growing between 2014 and 2019, with a non-significant regression in 2017, it evolved randomly.

Table 3 shows that the age of the patients varies between 35 to 90 years with an average age of $58.2 \pm 11.7$ years. The age group most affected was that of 50 to 59 years in a proportion of $39.39 \%$.

As shown in Table 4, men were the most affected with 26 cases (78.79\%) against $7(21.21 \%)$ for women. The sex ratio was 3.71:1 in favor of men.

In Table 5, married people represented a high proportion, i.e. $63.64 \%$ of cases.

Table 6 shows that most of our patients, or $45.45 \%$, resided in the commune of Bipemba.

Table 1. Distribution of cases according to hospital frequency of CRF.

\begin{tabular}{ccc}
\hline Frequency & not & $\%$ \\
\hline Chronic renal failure & 33 & 1.21 \\
Other pathologies & 2683 & 98.78 \\
Total & 2716 & 100.0 \\
\hline
\end{tabular}

Table 2. Distribution of cases according to the annual frequency of IRC.

\begin{tabular}{cccc}
\hline Year & Total number & IRC case & $\%$ \\
2014 & 476 & 5 & 0.18 \\
2015 & 570 & 7 & 0.26 \\
2016 & 501 & 6 & 0.22 \\
2017 & 437 & 4 & 0.15 \\
2018 & 381 & 6 & 0.22 \\
2019 & 351 & 5 & 0.18 \\
Total & 2716 & 33 & 1.21
\end{tabular}

Table 3. Distribution of CKD cases by age.

\begin{tabular}{ccc}
\hline Age (year) & not & $\%$ \\
\hline $0-9$ & 0 & 0 \\
$10-19$ & 0 & 0 \\
$20-29$ & 0 & 0 \\
$30-39$ & 1 & 3.03 \\
$40-49$ & 6 & 18.18 \\
$50-59$ & 13 & 39.39 \\
$60-70$ & 9 & 27.27 \\
$>70$ & 4 & 12.12 \\
Total & 33 & 100
\end{tabular}


Table 4. Distribution of IRC cases by sex.

\begin{tabular}{ccc}
\hline Sex & not & $\%$ \\
\hline Men & 26 & 78.79 \\
Women & 7 & 21.21 \\
Total & 33 & 100.00 \\
\hline
\end{tabular}

Table 5. Distribution of IRC cases by civil status.

\begin{tabular}{ccc}
\hline Civil status & not & $\%$ \\
\hline Married & 21 & 63.64 \\
Widower widow & 7 & 21.21 \\
Divorcee) & 4 & 12.12 \\
Single & 1 & 3.03 \\
Total & 33 & 100.00 \\
\hline
\end{tabular}

Table 6. Breakdown of IRC cases by origin.

\begin{tabular}{ccc}
\hline Origin & not & $\%$ \\
\hline Bipemba & 15 & 45.45 \\
Kanshi & 8 & 24.24 \\
Dibindi & 3 & 9.09 \\
Diulu & 3 & 9.09 \\
Muya & 2 & 6.06 \\
Out of town & 2 & 6.06 \\
Total & 33 & 100.00 \\
\hline
\end{tabular}

In Table 7, the reasons for admission were dominated by oligo-anuria, digestive disorders, dyspnea and physical asthenia with respectively $69.69 \%$ each.

As shown in Table 8, arterial hypertension, diabetes mellitus and acute renal failure were the antecedents found in the majority of our patients with successively $90.91 \% ; 84.85 \%$ and $66.67 \%$ of cases.

As shown in Table 9, the complete blood count revealed anemia $(\mathrm{Hb}<7 \mathrm{~g} / \mathrm{dl})$ at $81.9 \%$. The kidney ultrasound performed in our study revealed the kidneys to be $72.73 \%$ small.

Table 10 shows that the majority of patients, or $60.6 \%$, had end-stage chronic renal failure. The following Table gives the distribution of patients according to the stage of chronic renal failure.

As shown in Table 11, the healthy diet + medication was the most recommended treatment in $100 \%$ of cases. Dialysis was required in $81.82 \%$ of cases. Table 12 shows breakdown of IRC cases according to evolution.

As shown in Table 13, the majority of patients, i.e. $54.55 \%$, had a primary hospital stay less than or equal to 10 days. 
Table 7. Breakdown of IRC cases by reason for admission.

\begin{tabular}{ccc}
\hline Reasons for admission & $\mathbf{N}=33$ & $\%$ \\
\hline Oligo-anuria & 23 & 69.69 \\
Digestive disorders & 23 & 69.69 \\
Dyspnea & 23 & 69.69 \\
Physical asthenia & 20 & 60.61 \\
Dizziness & 19 & 57.57 \\
Nocturia & 15 & 45.45 \\
Polyuria & 10 & 30.30 \\
Coma & 10 & 30.30 \\
Weightloss & 4 & 12.12 \\
\hline
\end{tabular}

Table 8. Distribution of CKD cases by history.

\begin{tabular}{ccc}
\hline Antecedents & $\mathbf{N}=\mathbf{3 3}$ & $\%$ \\
\hline HTA & 30 & 90.91 \\
Diabetic sugar & 28 & 84.85 \\
Acute renal failure & 22 & 66.67 \\
Heart failure & 19 & 57.58 \\
Smoking & 15 & 45.45 \\
Dyslipidemia & 12 & 36.36 \\
Alcoholism & 11 & 33.33 \\
\hline
\end{tabular}

Table 9. Distribution of CKD cases according to the paraclinical report.

\begin{tabular}{lcc}
\hline Paraclinical assessment & not & $\%$ \\
\hline Anemia $(\mathrm{Hb}<7 \mathrm{~g} / \mathrm{dl})$ & 27 & 81.9 \\
High urea & 33 & 100 \\
Elevated creatinine & 33 & 100 \\
Blood sugar & 28 & 84.85 \\
High & 5 & 15.15 \\
Normal & 24 & 72.73 \\
Positive proteinuria & & \\
Hyperlipidemia & 16 & 48.48 \\
Yes & 17 & 51.52 \\
No & & 27.27 \\
Kidney ultrasound & 9 & 72.73 \\
Normal kidneys & 24 & \\
Small kidneys & & \\
\hline
\end{tabular}


Table 10. Distribution of CRF cases by stage of chronic renal failure.

\begin{tabular}{ccc}
\hline IRC stage & not & $\%$ \\
\hline Stage I & 4 & 12.12 \\
Stage II & 9 & 27.27 \\
Stage III & 8 & 24.24 \\
Stage IV & 12 & 36.36 \\
Total & 33 & 100 \\
\hline
\end{tabular}

Table 11. Distribution of IRC cases according to treatment.

\begin{tabular}{ccc}
\hline Treatment & $\mathbf{N}=\mathbf{3 3}$ & $\%$ \\
\hline Diet + medication & 33 & 100 \\
Reference for Dialysis & 27 & 81.82 \\
\hline
\end{tabular}

Table 12. Breakdown of IRC cases according to evolution.

\begin{tabular}{ccc}
\hline Evolution & not & $\%$ \\
\hline Stabilization/Reference & 27 & 81.81 \\
Death & 6 & 18.18 \\
Total & 33 & 100 \\
\hline
\end{tabular}

Table 13. Distribution of CKD cases according to the primary length of hospitalization.

\begin{tabular}{ccc}
\hline Hospital stay & not & $\%$ \\
\hline$\leq 10$ days & 18 & 54.55 \\
$>10$ days & 15 & 45.45 \\
Total & 33 & 100 \\
\hline
\end{tabular}

\section{Discussion}

\subsection{Age}

The age of our patients varies from 35 to 90 years with an average age of $58.2 \pm$ 11.7 years. The age group most affected was that of 50 to 59 years in a proportion of $39.39 \%$.

These results are almost similar to that found in France in 2007 [13], where 60\% of patients were over 60 years old. A study conducted in Tunisia in 2004 [14] reported that $40 \%$ of patients were over 60 years old.

Different results have been reported by other African studies. In fact, in Burkina Faso the average age was 36 years [15]. In Senegal $43.6 \%$ of patients were under 46 years old [16]. In Côte d'Ivoire, 57.3\% of patients under 45 were found [17]. Bourquia and Coll covered 55\% of the patients that have between 30 and 40 years [18].

The observation that emerges is that the pathology can occur at any age depending on the etiology. The high frequency in this age group could be explained 
by the hypothesis on the role of environmental factors, in particular smoking, alcoholism and occupational exposure in the onset and/or progression of renal pathologies.

\subsection{Sex}

Men were the most affected with 26 cases (78.79\%) against 7 (21.21\%) for women. The sex ratio was 3.71 in favor of men.

Comparable results to those found by Ahmed. [19], who had reported in his study $60 \%$ of male patients against $40 \%$ of the female sex, i.e. a sex ratio of $1.5 \mathrm{in}$ favor of men.

A comparable trend was noted in Senegal, Ivory Coast, and Morocco, i.e. respectively for the same parameter $54.4 \%, 61.8 \%, 59 \%$ [20] [21] [22]. For Mehier P., Burnier M. and Pruijm M, [23], the inequality of sex in the face of renal insufficiency remains for the moment not very thorough in humans. Most of the data come from veterinary studies which have shown that the higher incidence of renal failure in men is due to the lack of protective effect of endogenous estrogens in addition in women to hyper vascularization of the renal tissue and the Ability of renal cells to renew themselves. On may also include IgA nephropathy is diagnosed in young adults worldwide, common in whites and Asians than blacks.

\subsection{Reasons for Admission}

The reasons for admission were dominated by oligo-anuria, digestive disorders, dyspnea and physical asthenia.

A study carried out in Bamako in 2001 found the same reasons [18].

On the other hand Ahmed [19], had found in his study that hypercreatininemia represented $70 \%$ of the reasons for admission.

In Côte d'Ivoire the most dominant reason for consultations was hypertension with $40.83 \%$, followed by deterioration of the general condition with $12.23 \%$ [13].

\subsection{History}

Arterial hypertension, diabetes mellitus and acute renal failure were the antecedents found in the majority of our patients, i.e. in $90.91 \%$ respectively; $84.85 \%$ and $66.67 \%$ of cases. Ahmed [19] found that hypertension accounted for $52.6 \%$ of the medical history. A similar trend was observed in Senegal, $50.91 \%$ in favor of hypertension [20].

Hypertension is found as the most dominant antecedent, this demonstrates the importance of hypertension as an underlying factor in the occurrence of CRF. Hypertension and diabetes develop insidiously and induce cellular and microvascular damage without excluding the kidneys, often patients remain symptom-free for years. It is thus a diagnosis and an early assumption of responsibility is recommended. 


\subsection{Paraclinical}

In our study, the blood count revealed anemia $(\mathrm{Hb}<7 \mathrm{~g} / \mathrm{dl})$ in $81.9 \%$ of cases.

These results are close to those of Ahmed [19] who found in his study that $60.3 \%$ of cases had microcytic anemia, $42.7 \%$ had severe anemia with a hemoglobin level between 5 and $6.9 \mathrm{~g} / \mathrm{dl}$.

The kidney ultrasound performed in our study revealed the kidneys to be $72.73 \%$ small. Our data conform to international literature in that renal atrophy is often described in subjects with CRSD. It is the consequence of a decrease in the nephrotic capital which is the functional unit of the kidney.

A superimposable trend was reported by Kasadji [22], he found in $72.3 \%$ of cases small kidneys.

\subsection{Stage of Chronic Renal Failure}

The majority of patients, $60.6 \%$, had end-stage chronic renal failure. The predominance of the terminal stage of CRF is explained by the delay in the management of Patients with CRF.

These results are similar to a study carried out in Senegal where the frequency of terminal CKD was $65.5 \%$ [21].

\section{Conclusion}

Chronic renal failure is a common pathology in our community. It affects patients from their thirties, of both sexes. The majority of patients consult for oligo-anuria, digestive disorders, dyspnea and physical asthenia. High blood pressure and diabetes mellitus are the most common history. Most patients are admitted at the terminal stage. The lethality is quite high $(33.33 \%)$.

\section{Conflicts of Interest}

The authors declare no conflicts of interest regarding the publication of this paper.

\section{References}

[1] Ekoyau, G., Lameire, N., Barsoum, R., Eckardit, K.-U., Levin, A., Levin, N., et al. (2005) The Burden of Kidney Disease: Improving Global Outcomes. Kidney International, 66, 1310-1314. https://doi.org/10.1111/j.1523-1755.2004.00894.x

[2] Sumaili, E.K., Krzesinski, J.-M., Cohen, E.P. and Nseka, N.M. (2010) Epidemiology of Chronic Kidney Disease in the Democratic Republic of the Congo: A Synthetic Review of Studies from Kinshasa, the Capital. Nephrology \& Therapeutics, 6, 232-239.

[3] Benkaddour, N. (2011) Pre-Terminal Chronic Renal Failure in Adults in Hospitals 2011; Thesis No. 109/11: 8-9.

[4] (2015) Press Release. World Kidney Day.

[5] Stanifer, J.W., Jing, B., Tolan, S., et al. (2014) The Epidemiology of Chronic SubSaharan Africa: A Systematic Review and Meta-Analysis. The Lancet. Global Health, 2, e174-e181. https://doi.org/10.1016/S2214-109X(14)70002-6

[6] Diallo, A.D., Niamkey, E. and Yao, B.B. (1997) Chronic Renal Failure in Côte 
d'Ivoire: Study of 800 Hospitalized Cases. Bulletin de la Société de Pathologie Exotique, 90, 346-348.

[7] Sumali, E.K., Krzesinski, J.-M., Zinga, C.V., et al. (2009) Prevalence of Chronic Kidney Disease in Kinshasa: Results of Pilot Study from the Democratic Republic of Congo. Nephrology Dialysis Transplantation, 24, 117-122. https://doi.org/10.1093/ndt/gfn469

[8] Sumali, E.K., Cohen, E.P., Zinga, C.V., et al. (2009) High Prevalence of Undiagnosed Chronic Kidney Disease among At-Risk Population in Kinshasa, the Democratic Republic of Congo. BMC Nephrology, 10, 18.

[9] Patrick, R. (2017) Management of Chronic Renal Failure. Swiss Journal of Medicine, 13, 259-260.

[10] The SPRINT Research Group (2015) A Randomized Trial versus Standard BloodPressure Control. The New England Journal of Medicine, 373, 2013-2116. https://doi.org/10.1056/NEJMoa1511939

[11] Vogt, L., Whaanders, F., Boomsma, F., De Zeeuw, D. and Navis, G. (2008) Effects of Dietary Sodium and Hydrochlorothiazide on the Antiproteinuric Efficacy of Losartan. Journal of the American Society of Nephrology, 19, 999-1007. https://doi.org/10.1681/ASN.2007060693

[12] Stengel, B., Couchoud, C., Helmer, C., Loos-Ayav, C. and Kessler, M. (2019) Epidemiology of Chronic Renal Failure. Collective Expertise-Inserm-1.

[13] Couchoud, C., Stengel, B., Landais, P., Islnard, H., Jacquelinet, C., et al. (2006) The Renal Epidemiology and Information Network (REIN): A New Registry for ESRD in France. Nephrology Dialysis Transplantation, 21, 411-418. https://doi.org/10.1093/ndt/gfi198

[14] (2005) Treatment of IRCT in Tunisia: Realities-Strategic Choice.

[15] Kessler, M. (1998) Chronic Renal Failure: Etiology, Pathophysiology, Diagnosis, Principle of Treatment. Nephrology-Urology, 48, 1457-1463.

[16] Diouf, B., Niang, A., Ka, E.H., Badiane, M. and Diop, T.M. (2003) Chronical Renal Failure in One Hospital Department. Dakar Medical, 48, 185-188.

[17] Diallo, D.A. (1998) Chronic Hypertensive Nephropathies in Côte d'Ivoire. Black African Medicine, 45, 570-573.

[18] Bourquia, A. (1999) Current Status of Treatment for Chronic Renal Insufficiency in Morocco. Nephrology, 20, 75-80.

[19] Ahmed, M. (2006) Problem of the Management of Chronic Renal Insufficiency in Dialysis at the Hospital of the Point G. Thesis Med., Bamako, No. 91.

[20] Dia, K. (2002) Chronic Renal Failure in Hospital Dakaroi. Epidemioclinical Study. Thesis Med.

[21] Ngongangi, Y. (2002) High Digestive Complication of Uremia. About 40 Cases. Thesis Med.

[22] Mehier, P., Burnier, M. and Pruijm, M. (2017) Gender Inequality in Chronic Kidney Disease: Myth or Reality? Swiss Journal of Medicine, 13, 473-476.

[23] Kasadji, B. (2003) Chronic Renal Failure in the Nephrology Department of the Point G National Hospital. Epidemiological and Clinical Aspect. Thesis Med. 